\title{
CLASSIFICAÇÃO TAXONÔMICA (TERCEIRO TÁXON) DO RELEVO EM UM SETOR DOS DISTRITOS DE ARROIO GRANDE E PAINS EM SANTA MARIA, RS.
}

\author{
Naijara Klafke Dalla-Lana ${ }^{(a)}$, Rodrigo Correa Pontes ${ }^{(b)}$, Cibele Stefano ${ }^{(c)}$, Mauro Kumper. \\ Werlang ${ }^{(d)}$
}

(a) Departamento de Geociências/ Universidade Federal de Santa Maria, Email: naijaraklafke@ hotmail.com

(b) Departamento de Geociências /Universidade Federal de Santa Maria, Email: rodrigocorreapontes@ gmail.com

(c) Departamento de Geociências /Universidade Federal de Santa Maria, Email: cibele2012stefanno@ gmail.com

(d) Departamento de Geociências /Universidade Federal de Santa Maria, Email: wermakwer@gmail.com

\section{EIXO: SISTEMAS GEOMORFOLÓGICOS: ESTRUTURA, DINÂMICAS E PROCESSOS}

\begin{abstract}
Resumo
As formas ou os conjuntos de formas de relevo participam, em diferentes escalas, da composição geral do relevo. Nesse sentido, ao serem observadas num curto espaço de tempo se mostram com aparência estática. Porém, estão sendo continuamente trabalhadas por processos erosivos ou deposicionais. O propósito de estudar o relevo através das formas de modelado justifica-se no sentido de que a relação entre a erosão e a rede de drenagem é bastante estreita, permitindo qualificar a configuração da rede de drenagem como o resultado do trabalho erosivo. O relevo é um dos componentes do meio físico que apresenta grande diversidade de formas. Essas formas por mais que pareçam estáticas e iguais, são dinâmicas e manifestam-se no espaço de modo diferenciado face às combinações e interferências múltiplas dos demais componentes desse meio, podendo apresentar formas de acumulação, aplanamento e dissecação.
\end{abstract}

Palavras-chave: formas de relevo, rede de drenagem, erosão.

\section{Introdução}

Ao serem observadas num curto espaço de tempo as formas ou conjuntos de formas participam da composição do relevo em diferentes escalas. Nesse sentido, ao serem observadas num curto espaço de tempo se mostram com aparência estática. Porém, estão sendo continuamente trabalhadas por processos erosivos ou deposicionais. Nesse sentido, passa a existir uma necessidade maior de estudos que busquem conhecer e explicar morfologia do relevo. Portanto, o estudo do meio físico, entre eles o da geomorfologia, abrangendo o aspecto do modelado do relevo e do manejo dos recursos naturais, se reveste de grande importância especialmente no que diz respeito aos propósitos ambientais. Isso porque o relevo constitui o suporte para a articulação dos condicionantes de uso da terra pelas populações residentes nessas áreas.

O propósito de estudar o relevo através das formas de modelado justifica-se no sentido de que a relação entre a erosão e a rede de drenagem é bastante estreita, permitindo qualificar a configuração da rede de 
drenagem como o resultado do trabalho erosivo. O relevo é um dos componentes do meio físico e apresenta diversidade de formas. Ross (2003) destaca que essas formas por mais que pareçam estáticas e iguais, são dinâmicas e manifestam-se no espaço de modo diferenciado face às combinações e interferências múltiplas dos demais componentes desse meio. Apresenta formas de acumulação, aplanamento e dissecação. As formas de acumulação constituem as áreas onde predomina a acumulação, ou seja, aporte de material. Nas formas de aplanamento ocorre uma tendência de recuo e suavização das vertentes, mantendo o grau dos declives e, são ainda caracterizadas, pela manutenção da silhueta topográfica. Já as feições de dissecação, baseiam-se no grau de entalhamento dos vales e na dimensão interfluvial a partir da remoção de sedimentos (trabalho erosivo).

A concepção teórica do presente trabalho considera a abordagem de que a relação entre a configuração da drenagem (grau de entalhamento dos talvegues e dimensão interfluvial) e as formas de modelado do relevo (modelados de acumulação e dissecação) permite estabelecer uma relação de causa e efeito refletida nessas formas ou os conjuntos de formas. Assim, a densidade da drenagem é fator de influência no grau de dissecação do relevo. Essa, por conseguinte, é resultante da ação dos processos erosivos atuantes ao longo da vertente, que modelam o relevo.

\section{Objetivos}

O objetivo geral do trabalho foi contribuir para o entendimento do modelado do relevo em sua conformação nas diferentes formas, em um setor dos distritos de Arroio Grande e Pains, a leste da área urbana do Bairro Camobi, no município de Santa Maria, RS. O objetivo específico foi a classificação taxonômica do relevo (terceiro táxon) e o mapeamento de áreas com diferentes formas de modelado de um setor que abrange parte dos distritos de Arroio Grande e Pains, no município de Santa Maria, RS.

\section{Metodologia}

A área selecionada para o estudo está situada na região central do estado do Rio Grande do Sul, na Depressão Periférica Sul-riograndense (Ross, 1996) nas proximidades do Rebordo Planalto da Bacia Sedimentar do Paraná. Abrange parte da área urbana de Santa Maria, no Bairro Camobi e parte dos distritos de Arroio Grande e Pains. A área apresenta na sua porção norte e centro, formas características de ocupação urbana. Nas demais áreas aparecem características de ocupação rural, tendo como formas de uso predominantes a lavoura com arroz irrigado, lavouras temporárias e o campo com pastagem e pastoreio. 
A área abrangida pelo estudo está assentada sobre litologias da Formação Santa Maria (Membro Passo das Tropas e Membro Alemoa), Coberturas Terciárias formadas pelos Terraços Fluviais e, ainda, Sedimentos Atuais do Quaternário. Caracteriza-se por apresentar uma topografia suave e com baixas quotas altimétricas onde ocorre a planície aluvial do Rio Vacacaí-Mirim e os terraços fluviais depositados na várzea. A área da planície aluvial está constituída principalmente por sedimentos recentes (Quaternário) que foram removidos de superfícies topograficamente mais elevadas e depositados nas áreas mais planas das margens dos cursos fluviais. Modeladas sobre terraços fluviais em porções ao centro e sul ao sul da área, onde atuam processos de aplanamento e dissecação, ocorrem algumas formas topograficamente mais elevadas constituindo as colinas que, localmente são denominadas de coxilhas. Em alguns pontos, nessa área, formam-se coxilhas alongadas, apresentando-se na forma de pequenas encostas rampeadas. Nelas ocorrem processos de erosão hídrica a partir da atuação dos canais incisivos (sulcos e ravinas).

Em relação hidrografia, a área pertence ao sistema da bacia hidrográfica do Rio Vacacaí-Mirim. Essa apresenta um padrão de drenagem que, na classificação de Christofoletti (1980), enquadra-se no tipo subdentrítico uma vez que apresenta controle estrutural no curso fluvial principal. Entretanto, em alguns cursos d'àgua, o controle estrutural confere padrão sub-paralelo para a drenagem. A rede hidrográfica, na área de estudo, está representada por canais de primeira e segunda ordem. Estes canais são responsáveis pelas formas do modelado por meio do entalhamento dos talvegues e pela dissecação dos interflúvios.

A área abrangida pelo estudo sofreu significativas alterações na cobertura original da vegetação. Está inserida no domínio dos Campos com Capões e Matas Galerias (Vieira, 1984). Nos setores onde os processos erosivos esculpiram as colinas alongadas (coxilhas), sobre litologias Paleozóicas da Bacia do Paraná, aparecem solos medianamente profundos como os Argissolos. Nas áreas da planície e terraços fluviais, onde a flutuação do lençol freático, associado a uma conformação mais plana da topografia, imprime essa flutuação, influência sobre os processos pedogenéticos, ocorrem Gleissolos e Planossolos. O clima da região, com base na classificação de Köppen, apud Ayoade, (1986) enquadra-se como sendo Mesotérmico Brando Cfa. As precipitações são regulares durante todo o ano, não apresentando estação seca.

\section{Procedimentos metodológicos}

No desenvolvimento do trabalho foram utilizados materiais e instrumentos de laboratório, além de aplicativos computacionais. Os materiais utilizados foram: carta topográfica, aerofotogramas verticais pancromáticos preto e branco em escala 1: 15.000, imagens TM do Satélite LANDSAT-5, estereoscópio 


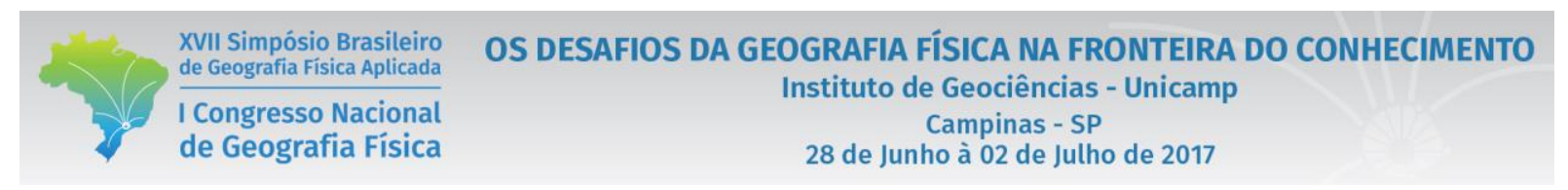

de bolso; estereoscópio de espelho com barra de paralaxe, papel acetato, lapiseira 0,5mm; grafite preto e colorido de 0,5mm, lupa de aumento, picareta, pá de corte e prancheta de campo.

O mapa-base foi obtido a partir da folha topográfica de Camobi-SE da Diretoria do Serviço Geográfico do Exército-DSG, em escala de 1: 25.000. Também nesta etapa de elaboração do mapa-base foram utilizadas imagens do sensor TM LANDSAT-5, onde, através da interpretação visual sobre a composição colorida 3/4/5, observaram-se os padrões gerais da área (uso da terra, rede de drenagem, cobertura pedológica). Com o apoio dos aerofotogramas verticais, delimitou-se a área de estudo e obteve-se o detalhamento das informações planialtimétricas e do modelado do relevo. Obedecendo a proposta metodológica de Libault (1971) que adota os níveis da pesquisa geográfica em nível compilatório; nível correlatório; nível semântico e nível normativo, essas informações foram compiladas e, com o auxílio do aplicativo computacional gráfico Corel DRAW X $3^{\circledR}$, foi então obtido o mapa do modelado do relevo da área em estudo.

Na determinação do modelado de dissecação consideraram-se as áreas onde se configura uma morfologia caracterizada como relevo de degradação e, para a obtenção das informações relativas ao modelado de dissecação, tomou-se como referência a matriz dos índices de dissecação adaptada de Ross (1994) e Ross (1996). Essa se baseia em informações da dimensão interfluvial média nas colunas horizontais e entalhamento médio dos vales nas colunas verticais, conforme pode ser visualizado no quadro 1.

Pela disposição dos dados constantes do quadro 1, observa-se que na dimensão interfluvial média os valores são inversamente proporcionais, ou seja, quanto maior a densidade de drenagem menor a dimensão interfluvial média. Com relação ao índice de dissecação, o menor valor numérico é a dissecação mais fraca (11) e o maior valor numérico é a dissecação mais forte (55). Dessa forma as categorias morfométricas ficam classificadas em:

1-Muito Fraca..................da matriz...11

2-Fraca.........................da matriz...21, 22, 12

3-Média.........................da matriz...31, 32, 33, 13, 23

4-Forte...........................da matriz...41, 42, 43, 44, 14, 24, 34

5-Muito Forte................da matriz...51, 52, 53, 54, 55, 15, 25, 35, 45 


\begin{tabular}{|c|c|c|c|c|c|}
\hline \multicolumn{2}{|c|}{$\begin{array}{l}\text { XVII Simpósio Brasileiro } \\
\text { de Geografia Fisica Aplicada } \\
\text { I Congresso Nacional } \\
\text { de Geografia Física }\end{array}$} & \multicolumn{4}{|c|}{$\begin{array}{l}\text { OS DESAFIOS DA GEOGRAFIA FÍSICA NA FRONTEIRA DO CONHECIMENTO } \\
\text { Instituto de Geociências - Unicamp } \\
\text { Campinas - SP } \\
28 \text { de Junho à } 02 \text { de Julho de } 2017\end{array}$} \\
\hline 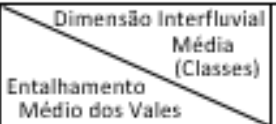 & $\begin{array}{l}\text { Muito Grande (1) } \\
\quad>750 \mathrm{~m} \\
\quad>15 \mathrm{~mm}\end{array}$ & $\begin{array}{l}\text { Grande (2) } \\
750 \text { a } 350 \mathrm{~m} \\
7 \text { a } 15 \mathrm{~mm}\end{array}$ & $\begin{array}{l}\text { Média (3) } \\
>350 \text { a } 150 \mathrm{~m} \\
3 \text { a } 7 \mathrm{~mm}\end{array}$ & $\begin{array}{l}\text { Pequena (4) } \\
150 \text { a } 50 \mathrm{~m} \\
1 \text { a } 3 \mathrm{~mm}\end{array}$ & $\begin{array}{l}\text { Muito Pequena } \\
\text { (5) }<50 \text { a } 1 \mathrm{~mm}\end{array}$ \\
\hline $\begin{array}{c}\text { Muito Fraca (1) } \\
(<\text { de } 20 \mathrm{~m})\end{array}$ & 11 & 12 & 13 & 14 & 15 \\
\hline $\begin{array}{c}\text { Fraco }(2) \\
(20 \text { a } 40 \mathrm{~m})\end{array}$ & 21 & 22 & 23 & 24 & 25 \\
\hline $\begin{array}{l}\text { Médio (3) } \\
(40 \text { a } 80 \mathrm{~m})\end{array}$ & 31 & 32 & 33 & 34 & 35 \\
\hline $\begin{array}{c}\text { Forte (4) } \\
(80 \text { a } 160 \mathrm{~m})\end{array}$ & 41 & 42 & 43 & 44 & 45 \\
\hline $\begin{array}{l}\text { Muito Forte (5) } \\
(>160 \mathrm{~m})\end{array}$ & 51 & 52 & 53 & 54 & 55 \\
\hline
\end{tabular}

Quadro 1 - Matriz dos índices de dissecação do relevo adaptada para a escala 1: 50000 e empregada na classificação taxonômica do relevo (terceiro táxon) e no mapeamento de áreas com diferentes formas de modelado do setor que abrange parte dos distritos de Arroio Grande e Pains, no município de Santa Maria, RS. Fonte: Adaptado de Ross (1996).

$\mathrm{Na}$ coluna da dimensão interfluvial média os valores mais altos dos interflúvios estão à esquerda, diminuindo para a direita. Já nas colunas verticais os algarismos arábicos crescem do topo para a base da matriz, do menor para o maior grau de entalhamento. Esta metodologia consiste em estudar todos os canais de primeira ordem. Esses foram obtidos dos aerofotogramas verticais onde se efetuaram medidas das distâncias médias (obtidas de três medidas) entre os interflúvios através da equação1 (ROCHA, 1986):

$$
\begin{gathered}
\frac{1}{M}=\frac{d}{D} \quad(\text { equação } 1) \\
\text { onde: } \\
M=\text { módulo escalar do aerofotograma; } \\
d=\text { distância gráfica; } \\
D=\text { distância real. }
\end{gathered}
$$

O grau de entalhamento dos canais foi obtido através da equação 2 (ROCHA, 1986):

$$
\begin{gathered}
\boldsymbol{H} z=\frac{\boldsymbol{h} v \cdot \Delta \boldsymbol{p x}}{\boldsymbol{b}+\Delta \boldsymbol{p x}} \quad(\text { equação } 2) \\
\text { onde: } \\
H z=\text { altura; } \\
h v(\text { altura de vôo })=\frac{1}{m}=\frac{f}{h v} \therefore h v=(f . m) \\
f=\text { distância focal; }
\end{gathered}
$$




\section{OS DESAFIOS DA GEOGRAFIA FÍSICA NA FRONTEIRA DO CONHECIMENTO \\ Instituto de Geociências - Unicamp \\ Campinas - SP \\ 28 de Junho à 02 de Julho de 2017}

$m=$ módulo escalar;

$\Delta p x($ diferença de paralaxe $)=p x a-p x b$;

pxa $=$ paralaxe do ponto $\mathrm{a}$;

$p x b=$ paralaxe do ponto $\mathrm{b}$

$b($ base estereoscópica $)=\frac{b 1+b 2}{2}$

Para a obtenção das informações relativas ao modelado do relevo de acumulação, essas foram determinadas tendo-se como referência as áreas formadas a partir da deposição de sedimentos trazidos de áreas adjacentes mais altas, configurando a morfologia como relevo de agradação. Para o modelado de aplanamento, esse foi caracterizado pelas áreas levemente onduladas nas bordas dos divisores orográficos e ressaltos topográficos.

\section{Resultados e discussão}

A figura 1 mostra o modelado do relevo (terceiro táxon) obtido para o setor que abrange parte dos distritos de Arroio Grande e Pains, no município de Santa Maria, RS.

Os resultados obtidos (figura 1) indicam que a área apresenta, ao norte e a oeste, o predomínio da planície aluvial do Rio Vacacaí-Mirim, correspondendo a sedimentação do Quaternário e predomínio de formas de acumulação. Nessas formas estão presentes áreas alagadiças, terraços fluviais e nichos de nascentes. Alguns terraços fluviais apresentam setores com vertentes convexas, formando interflúvios, onde ocorrem modelados de dissecação. Na porção centro e sul da área estão presentes, predominantemente, modelados de dissecação, que ocorrem sobre setores de vertentes convexas assentadas sobre Argissolos desenvolvidos a partir de litologias da Formação Santa Maria (Membro Alemoa e Membro Passo das Tropas).

A área da planície aluvial, excetuando-se os terraços fluviais que nela estão constituindo modelados de dissecação, apresenta relevo de agradação. Nela registra-se a ocorrência de Plintossolos (nos terraços), Planossolos e Gleissolos (na várzea), além de da ocorrência de Cambissolos (em setores intermediários entre os terraços e a várzea). O modelado de acumulação está, portanto, caracterizado pela ocorrência de solos mal drenados e com incremento de argila em profundidade, presença de mosqueados e cores escuras e acinzentadas caracterizando um processo de flutuação do nível freático com moderada gleização. Áreas com modelado de acumulação estão localizadas principalmente na várzea do rio Vacacaí-Mirim, mas também ocorrem em alguns dos cursos fluviais que recebem aporte de material de áreas adjacentes. 


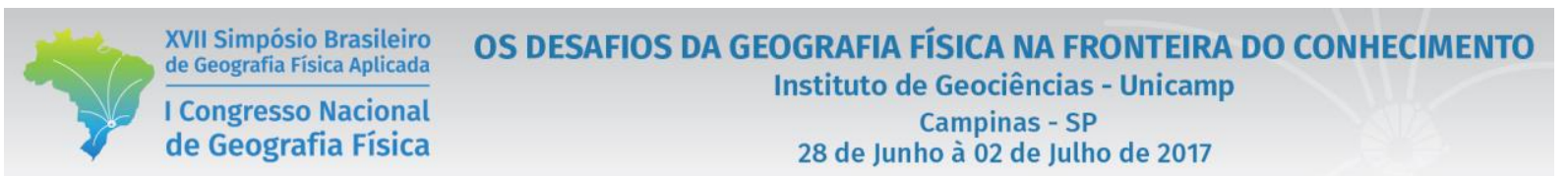

Caracterizam-se por apresentar processos de coluviação e deposição fluvial onde se encontram sedimentos pouco consolidados. São áreas que recebem cultivos anuais como a produção de arroz irrigado e, são também empregadas, para uso com pecuária. Essas áreas estão suscetíveis a inundações periódicas, sendo essa a principal limitação quanto ao uso da terra.

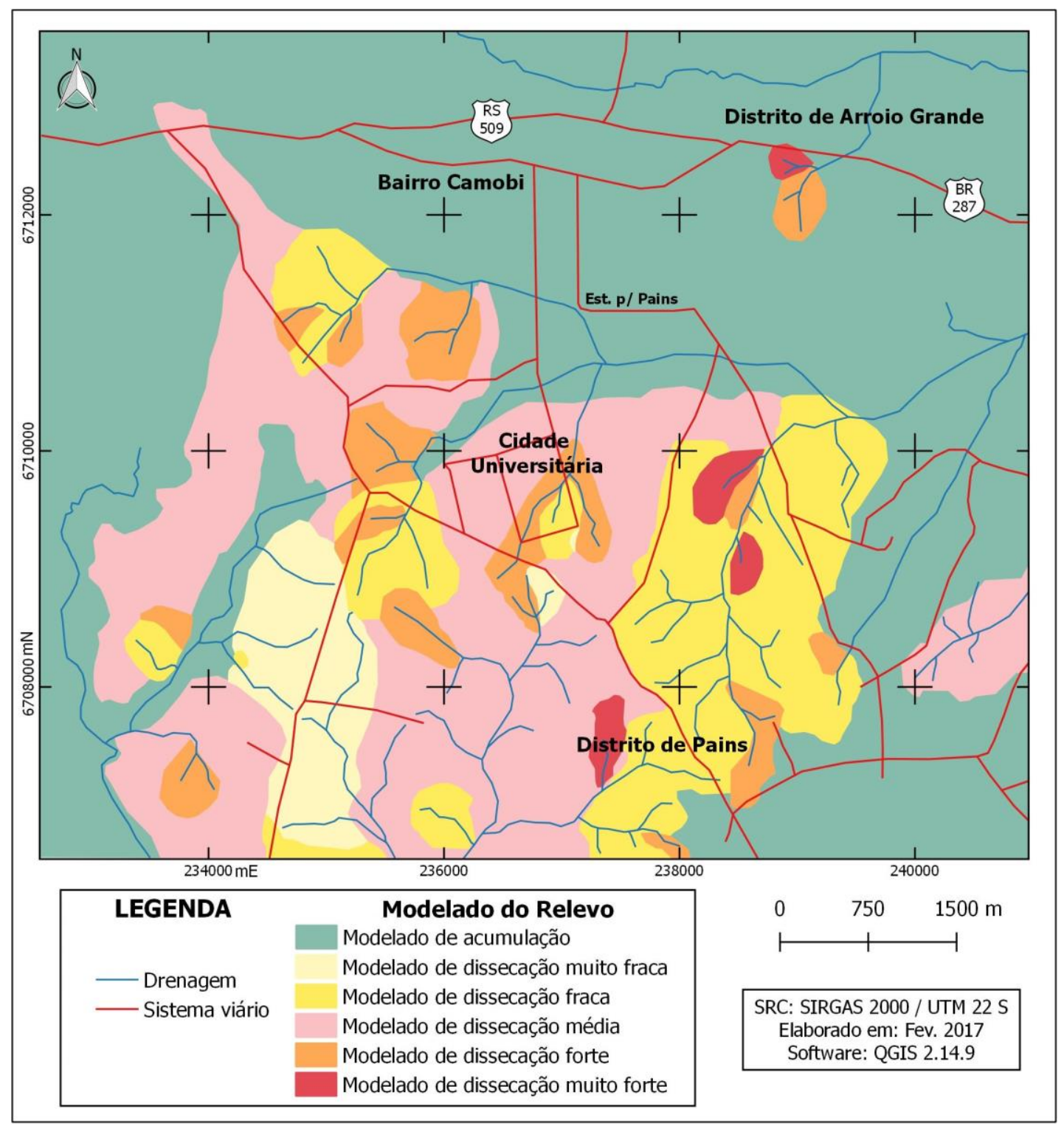

Figura 1. Modelado do relevo (terceiro táxon) obtido para o setor que abrange parte dos distritos de Arroio Grande e Pains, no município de Santa Maria, RS.

O modelado de dissecação de relevo ocorre principalmente na parte centro e sul da área de estudo. Estas áreas apresentam declividade variável e maior densidade na drenagem. Apresentam topografia suave 
ondulada e vertentes com perfil convexo-côncavo. Em alguns setores das vertentes, se observa processos de erosão desenvolvidos partir de canais incisivos e do escoamento entressulcos. Nas vertentes com maior grau de declividade são comuns os processos de erosão acelerada. Em algumas vertentes ocorre a presença de anfiteatros erosivos em cabeceiras de drenagem. Nesses setores da área de estudo, onde ocorrem modelados de dissecação, existem áreas que apresentam condicionantes que oferecem restrições ao uso da terra requerendo práticas conservacionistas. Neles ocorrem Argissolos e estão sendo com agricultura e pecuária.

Também os resultados obtidos, constantes no mapa da figura 1, mostram o predomínio do modelado de acumulação. Esse modelado corresponde ás áreas de acumulação aluvial na várzea do Rio Vacacaí-Mirim. Essa sedimentação do Quaternário é localmente caracterizada por sedimentos areno-argilosos e arenosiltosos. Engloba as formas originadas por processos de deposição fluvial (agradação) onde se encontram sedimentos detríticos pouco consolidados. Em algumas áreas dentro da várzea aparecem terraços fluviais com modelado de dissecação. Esses se apresentam, por vezes, como superfícies inumadas. As vertentes, em algumas situações, apresentam perfil com segmento côncavo-convexo, em outras, perfil convexo, caracterizando feições do domínio geomorfológico da Depressão Periférica Sul-riograndense. O resultado obtido mostra também significativa área abrangida pelo modelado de dissecação. Esse modelado caracteriza os setores intermediários entre a planície e as coxilhas. Também ocorre em áreas junto as nascentes de diversos cursos d'água. Caracteriza setores com maior grau de declividade e maior densidade de canais fluvias. Esses setores, principalmente naqueles onde ocorrem os nichos de nascente, merecem atenção especial quanto ao manejo e uso da terra.

\section{Conclusão}

Os resultados obtidos destacam que a declividade e a densidade da drenagem (dimensão interfluvial e o grau de entalhamento) estão associadas ao grau de dissecação do relevo. Mostram que na área há o predomínio do modelado de acumulação e que esse revela o processo de agradação e que o modelado de dissecação caracteriza os processos d e degradação. Estes modelados, no terceiro táxon, correspondem a unidades morfológicas ou de padrões de formas semelhantes (modelado) que constituem conjuntos menores de formas do relevo, apresentando um padrão de semelhança entre si em função da rugosidade topográfica, bem como do formato de topos, vertentes e vales de cada padrão. Neste táxon, os processos morfoclimáticos atuais são mais facilmente notados, podendo-se identificar os agrupamentos de formas de agradação (relevo de acumulação) e formas de denudação (relevo de dissecação). 
Conclui-se que a classificação taxonômica do relevo, no terceiro táxon, corrobora com a concepção teórica proposta. Permite, portanto, afirmar que a relação entre a configuração da drenagem (grau de entalhamento dos talvegues e dimensão interfluvial) e as formas de modelado do relevo (modelados de acumulação e dissecação) estabelece uma relação de causa e efeito refletida nas formas ou nos conjuntos de formas do relevo.

\section{Bibliografia}

AYOADE, J. Introdução a climatologia dos trópicos. São Paulo-SP: Difel, 1986.

CRHISTOFOLETTI, A. Geomorfologia. São Paulo-SP: Edgard Blücher, 1980.

GUERRA, A.T. Dicionário Geológico-Geomorfológico. 7 ed. Rio de Janeiro, RJ: FIBGE; 1987.

LIBAULT, A. Os quatro níveis da pesquisa geográfica. Métodos em Questão. n 1 , São Paulo, SP:

IGEO/USP,1971.

ROCHA, J.S. M da. Manual de interpretação de aerofotogramas. Santa Maria, RS: DER-CCR/UFSM. 1986. Fascículo I. (publicação avulsa)

ROSS, J.L. Análise empírica da fragilidade dos ambientes naturais e antropizados. Revista do Departamento de Geografia. São Paulo, SP: DGEO, n. 8, p. 63-74, 1994.

ROSS, J.L. Geografia do Brasil. São Paulo, SP: Edusp, 1996.

ROSS, J.L. Geomorfologia: ambiente e planejamento. São Paulo, SP: Contexto, 2003.

VIEIRA, E.F. Rio Grande do Sul. Geografia física e vegetação. Porto Alegre, RS: Sagra, 1984. 